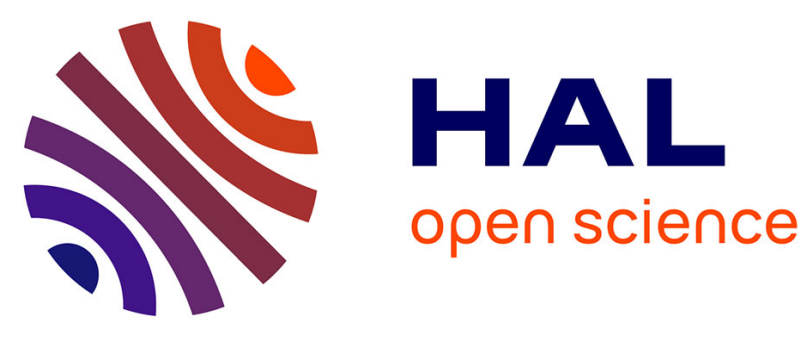

\title{
Modeling and fabrication of piezoelectric aluminium nitride resonator and its application in oscillators
}

Olivier Mareschal, Sebastien Loiseau, Fabrice Verjus, Laurie Valbin, Gaelle

Bazin Lissorgues, R. Bouregba, G. Poullain, Sébastien Saez, Christophe Dolabdjian

\section{To cite this version:}

Olivier Mareschal, Sebastien Loiseau, Fabrice Verjus, Laurie Valbin, Gaelle Bazin Lissorgues, et al.. Modeling and fabrication of piezoelectric aluminium nitride resonator and its application in oscillators. Solid-State Sensors, Actuators and Microsystems Conference, 2009, Denver, United States. pp.565568, 10.1109/SENSOR.2009.5285387 . hal-00989687

\section{HAL Id: hal-00989687 https://hal.science/hal-00989687}

Submitted on 13 May 2014

HAL is a multi-disciplinary open access archive for the deposit and dissemination of scientific research documents, whether they are published or not. The documents may come from teaching and research institutions in France or abroad, or from public or private research centers.
L'archive ouverte pluridisciplinaire HAL, est destinée au dépôt et à la diffusion de documents scientifiques de niveau recherche, publiés ou non, émanant des établissements d'enseignement et de recherche français ou étrangers, des laboratoires publics ou privés. 


\title{
MODELING AND FABRICATION OF PIEZOELECTRIC ALUMINUM NITRIDE RESONATOR AND ITS APPLICATION IN OSCILLATORS
}

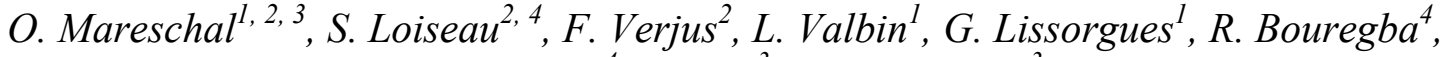 \\ G. Poullain ${ }^{4}$, S. Saez ${ }^{3}$, C. Dolabdjian ${ }^{3}$ \\ ${ }^{1}$ ESIEE-ESYCOM, Université Paris-Est, Noisy-le-Grand, France \\ ${ }^{2}$ NXP Semiconductors, Caen, France \\ ${ }^{3}$ GREYC (CNRS UMR6072), ENSICAEN \& Université de Caen, France \\ ${ }^{4}$ CRISMAT (CNRS UMR6508), ENSICAEN \& Université de Caen, France
}

\begin{abstract}
This work investigates the TFEAR (Thin Film Elongation Acoustic Resonator) [1] operating at $\mathrm{MHz}$ frequencies. This resonator is composed of a piezoelectric Aluminum Nitride (AIN) layer sandwiched between two aluminum (Al) electrodes. The resonators are manufactured on a silicon substrate. In opposition to common resonator, TFEAR works in extensional (elongation) mode excited via AlN $d_{31}$ piezoelectric coefficient. A Finite Element Analysis is performed to simulate the static and modal behaviors. The simulation is used to determine the geometry of each material so as to reach the desired frequency range and to compare theoretical and experimental results at different resonance frequencies. A modified Van-Dyke Butterworth (MBVD) equivalent circuit model is developed, including substrate losses. Samples have been measured and quality factor as high as 2500 in air have been measured. A first oscillator based on TFEAR resonator was designed and fabricated. Results are discussed.
\end{abstract}

\section{KEYWORDS}

Piezoelectric resonator, oscillator, aluminum nitride, elongation mode

\section{INTRODUCTION}

More and more industrial electronic applications, like Universal Serial Bus (USB), Radio Frequency Identification (RFID), or Personal Digital Assistant (PDA), needs smaller, lower power consumption and cheaper systems. Usually, quartz is used for clock reference oscillators. Conventional quartz resonators are millimeter sized, and are not silicon compatible. A solution is to develop Micro-Electro-Mechanical Systems (MEMS) resonators which are micrometer sized and mostly integrated circuit compatible. Bulk Acoustic Wave (BAW) resonators are now used in some applications in the $\mathrm{GHz}$ range frequencies. The aim of TFEAR is to be an alternative for quartz crystal resonators in the $\mathrm{MHz}$ range frequencies. $\mathrm{MHz}$ frequencies electrostatic resonators have been presented in earlier papers [2]. Disadvantage of those solutions is the high voltage value needed to polarize the resonators. Piezoelectric resonators do not need this voltage and consequence is lower power consumption.
In this paper, we first address the TFEAR principle, particularly its excitation mode. Physical model will be presented in the first section. The second section deals with the fabrication process. Process flow will be described with a particular attention for the AIN deposition. Then, the MBVD equivalent circuit, used to mimic the TFEAR behavior, will be presented. Finally, results of characterization for oscillator application will be shown and compared to theory and simulation.

\section{PRINCIPLE}

\section{Thin Film Elongation Acoustic Resonator (TFEAR)}

TFEAR consists of a multilayer beam constituted of insulator-metal-piezoelectric-metal materials. Transverse piezoelectric coefficient $d_{31}$ of the AlN piezoelectric layer is used [3]. Consequently, a driving voltage applied on the piezoelectric thin film allows beam elongation. The name "TFEAR" comes from the propagation of bulk acoustic waves along the length of the beam.

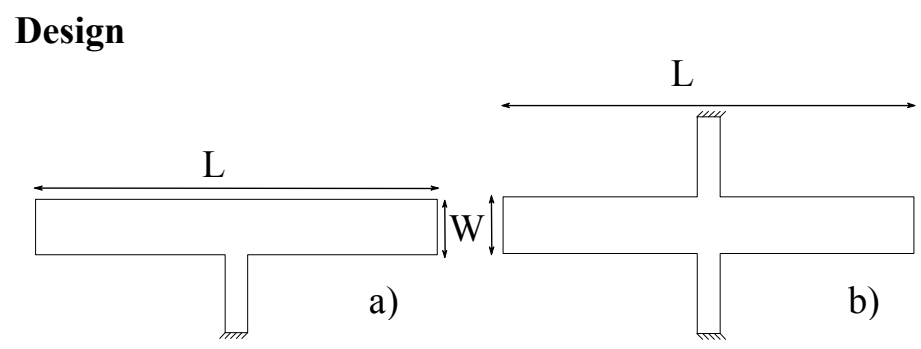

Figure 1: Schematic view of T-shaped (a) and X-shaped (b) TFEAR.

TFEAR consists of AlN film $(1 \mu \mathrm{m})$ sandwiched between two Al electrodes $(0.2 \mu \mathrm{m}$ each $)$. AlN material has those advantages to be a non-contaminant piezoelectric material (in opposition to the lead present in the PZT) and presents high acoustic wave velocity [4]. Two designs were investigated during this study. The first consists of a $\mathrm{T}$-shaped beam anchored at its base end and the second consists of an X-shaped beam anchored at each base ends, as it is shown in Figure 1. For each design, the mask allows to make many samples which present various lengths and widths between $75 \mu \mathrm{m}$ and $350 \mu \mathrm{m}$, and $20 \mu \mathrm{m}$ or $50 \mu \mathrm{m}$ respectively. The range of the frequency is tuned by the length of the beam forming the resonator. 
Figure 1(a) and Figure 1(b) present the piezoelectric layer shape. The excitation voltage is applied on Al electrode deposited on the entire piezoelectric layer.

\section{Process steps}

The resonator is manufactured on (100) oriented high resistivity silicon wafers. TFEAR is fabricated using conventional integrated circuit manufacturing tools. Figure 2 presents a schematic process flow. First, the silicon substrate is thermally oxidized (a). Pads ( $\mathrm{AlSi}_{1 \%} \mathrm{Cu}_{0.04 \%}$ ) are deposited by DC-magnetron sputtering tool (b). Bottom electrode $\left(\mathrm{AlSi}_{1 \%} \mathrm{Cu}_{0.04 \%}\right)$ is also deposited by DCmagnetron sputtering tool (c). Thereafter, AlN layer is deposited by DC or pulsed DC reactive sputtering in nitrogen and argon atmosphere (d). Top electrode is deposited like bottom electrode (e). These four layers are patterned by dry etching for the $\mathrm{AlSi}_{1 \%} \mathrm{Cu}_{0.04 \%}$ and by wet etching for the AIN layer. Finally, TFEAR is released by designing of the cavity (f) using anisotropic and isotropic dry etching for the silicon oxide layer and the silicon substrate, respectively.

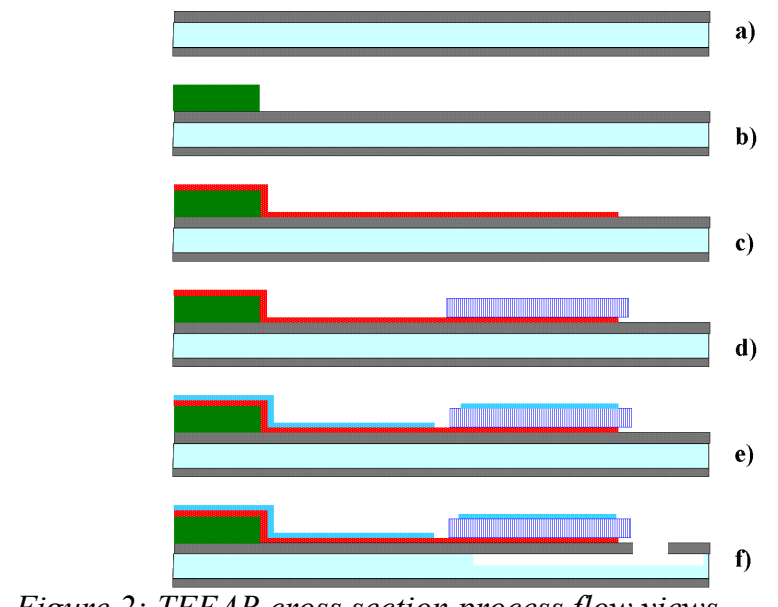

Figure 2: TFEAR cross section process flow views.

The Figure 3 shows an example of a SEM view of a TFEAR fabricated on the above conditions.

\section{AlN deposition}

Regarding the piezoelectric AlN layer, under-layers have to be optimized to have the best crystallized material. Indeed, the most crystallized material leads to the highest piezoelectric coefficient $d_{31}$ characterizing the beam.

Thermal oxide shows better results compared to oxide grown by Low Pressure Chemical Vapor Deposition (LPCVD) and oxide grown by Plasma Enhanced CVD (PECVD). Then thermal oxide was chosen for the insulator layer. Designs of experiments were used to optimize the deposition parameters of $\mathrm{AlSi}_{1 \%} \mathrm{Cu}_{0.04 \%}$ and AlN layers in order to get the highest crystallinity of AlN with DC or pulsed-DC magnetron sputtering. The aim was achievement of the best crystallinity of the AlN characterized by X-Ray Diffraction (XRD) and thus, the best piezoelectric property and the highest Q factor with the complete resonator. The best results were achieved with the pulsed-DC magnetron sputtering tool (OERLIKON clusterline 200).

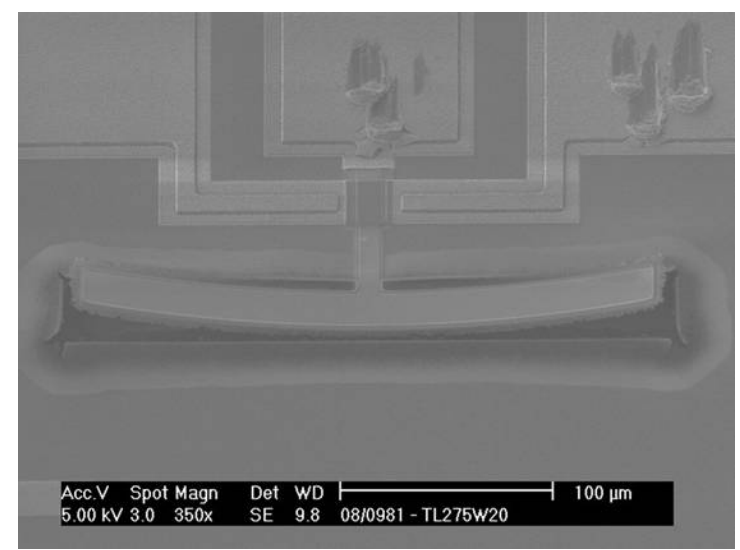

Figure 3: SEM view of a $75 \mu \mathrm{m}$ length and $20 \mu \mathrm{m}$ width TFEAR.

\section{PHYSICAL MODEL}

Simulations, made with ANSYS software, have been performed to analyze different designs and to predict expected resonance frequencies. The simulation takes into account the electrodes and the part of the substrate ( $\mathrm{Si}$ ) where beam is anchored.

According to geometrical parameters, the reachable resonance frequency $f_{s}$, of such sample is in the $10 \mathrm{MHz}-$ $50 \mathrm{MHz}$ range according to the relation:

$$
f_{s}=\frac{1}{2 L} \sqrt{\frac{\bar{E}}{\bar{\rho}}}
$$

Where $L$ is the length of the beam, $E$ is equivalent Young modulus of the stacked layers, and $\rho$ is the beam equivalent density. These two properties are balanced with the thickness of each layer and can be expressed by:

$$
\bar{E}=E_{A I N} \times t_{A I N}+E_{A l}\left(t_{A l_{\text {top }}}+t_{A l_{\text {botom }}}\right)
$$

and

$$
\bar{\rho}=\rho_{A I N} \times t_{A l N}+\rho_{A l}\left(t_{A l_{\text {top }}}+t_{A l_{\text {botom }}}\right)
$$

where, $t_{A I N}, t_{A l_{\text {top }}}$, and $t_{A l_{\text {botom }}}$ are the thickness of AlN, Al top and $\mathrm{Al}$ bottom layers respectively. $E_{A I N}$ and $E_{A l}$ are the Young modulus, $\rho_{A I N}$ and $\rho_{A l}$, the mass density of AlN and Al layers respectively.

\section{ELECTRICAL MODEL}

To describe resonator electrical behaviors, the model based on Van-Dyke Butterworth equivalent circuit used [5] is presented in Figure 4. $R_{m}, L_{m}$ and $C_{m}$ represent the equivalent resistance, inductance and capacitance of the motional branch and $\mathrm{C}_{0}$ the static capacitance of TFEAR electrodes. Additional parallel resistor $R_{p}$ represents the dielectric losses of the AlN layer. $C_{s u b}$ and $R_{\text {sub }}$ represent substrate and connection pads elements.

$C_{s u b}$ can be evaluated by estimating the capacitance of 
pads connections and substrate and by testing the substrate behavior with DC polarization. The quality factor $Q$ of the equivalent circuit is given by:

$$
Q=\frac{1}{R_{m}} \sqrt{\frac{L_{m}}{C_{m}}} .
$$

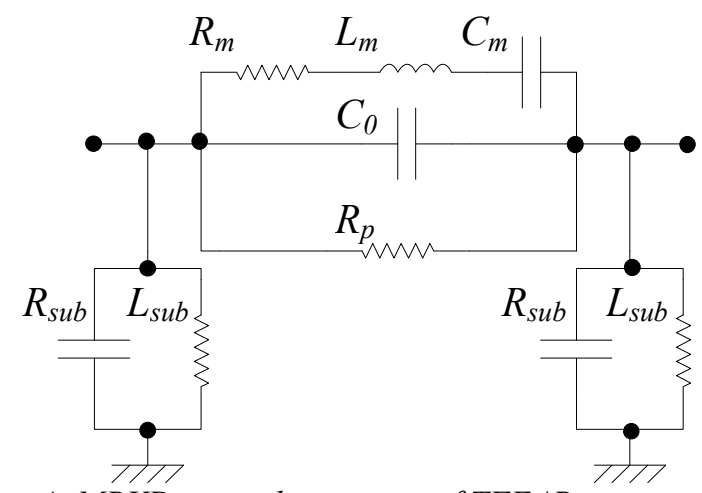

Figure 4: MBVD equivalent circuit of TFEAR.

\section{CHARACTERIZATION AND RESULTS Characterization of resonators}

On-wafer level measurements are performed using semi automated prober Electroglass 2001X with thermal chuck.

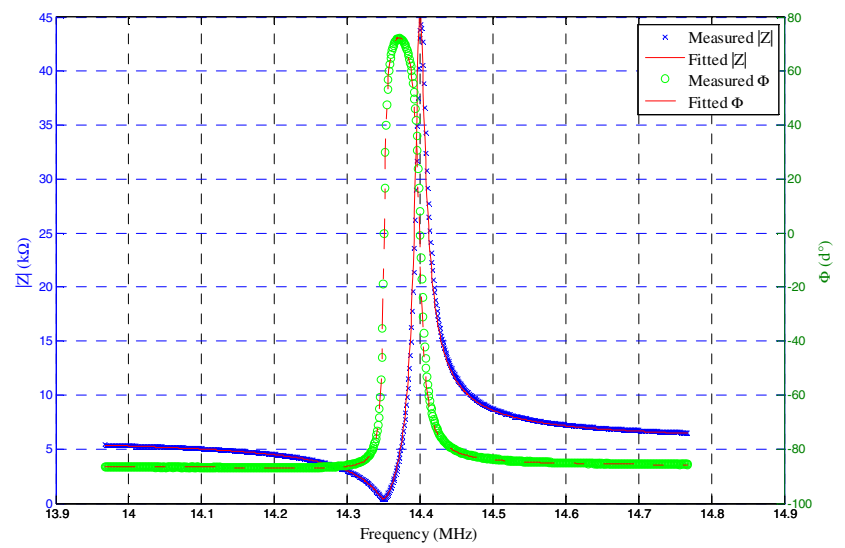

Figure 5: Examples of measured and fitted impedance amplitude and phase.

Impedance of TFEAR is measured using Agilent 4194A with impedance probe kit. TFEAR is driven by a $25 \mathrm{mV}$ signal to work in linear state. The resonance frequencies were previously estimated by simulation which permits to sweep over a frequency range around those values for each sample. The amplitude and phase of the impedance is recorded. Because one of the pads and the substrate are connected to the ground, the electrical model presented in the Figure 4 can be simplified, considering $R_{p}^{\prime}=R_{\text {sub }} \| R_{p}$ and $C^{\prime}{ }_{0}=C_{\text {sub }} \| C_{0}$ represent the total resistance and capacity of the resonator measured on the substrate, respectively.

Matlab post-processing allows to extract equivalent circuit parameters and fit is performed. The Figure 5 presents measured and fitted curves for a $350 \mu \mathrm{m}$ length, $50 \mu \mathrm{m}$ width, T-shaped resonator using $\mathrm{SiO}_{2}$ insulating layer. Table 1 shows results for a TFEAR, quality factor $Q$ is calculated using formula 4.

Table 1: Measured MBVD elements, resonance frequency and quality factor of a fabricated TFEAR.

\begin{tabular}{|c|c|}
\hline TFEAR & $350 \mu \mathrm{m}$ \\
\hline $\mathrm{R}_{\mathrm{m}}(\Omega)$ & 376.4 \\
\hline $\mathrm{L}_{\mathrm{m}}(\mathrm{mH})$ & 9.6 \\
\hline $\mathrm{C}_{\mathrm{m}}(\mathrm{fF})$ & 12.8 \\
\hline $\mathrm{C}^{\prime}{ }_{0}(\mathrm{pF})$ & 1.88 \\
\hline $\mathrm{R}^{\prime}{ }_{\mathrm{p}}(\mathrm{k} \Omega)$ & 8.9 \\
\hline $\mathrm{f}_{\mathrm{s}}(\mathrm{MHz})$ & 14.3505 \\
\hline $\mathrm{Q}$ & 2300 \\
\hline
\end{tabular}

\section{Resonance frequency and geometry}

Figure 6 shows the resonance frequency as a function of the inverse length of T-shaped TFEAR. Resonance frequencies from $10 \mathrm{MHz}$ to $50 \mathrm{MHz}$ have been measured. We can notice the well matching between measurements and simulation results for wafer 1 .

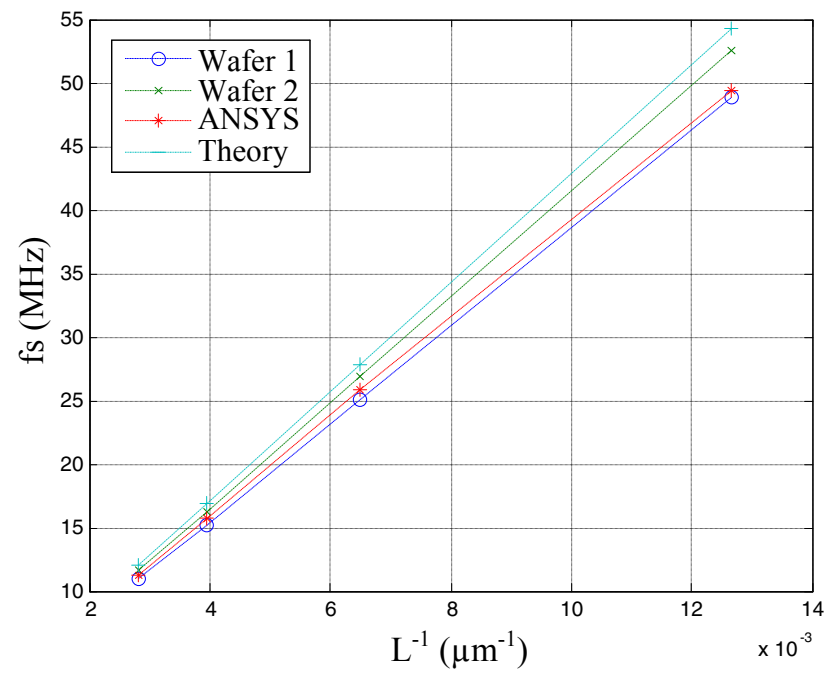

Figure 6: Resonance frequency as a function of resonator length.

Wafer 2 results show a good agreement with theory calculated from equation 1. During the fabrication of TFEAR, alignment errors could occur and some other process problems could appear for each step, which can explain curve divergences for higher frequencies (lower length). Other parameters, like inductive and resistive components of the access line, are not represented and the piezoelectric coefficients used to simulate the AlN layer are theoretical values [4]. Work is in progress to include these new parameters in the model and to characterize thin film used. This will improve fitting between theory, simulation and measurements. 


\section{Resonance frequency and temperature}

The temperature dependency of the frequency resonance is evaluated by extracting the figure of merit, Temperature Coefficient Frequency $(T C F)$, following the relation:

$$
T C F=\frac{\Delta f / \Delta T}{f_{s}} \times 1.10^{6}\left(\mathrm{ppm} /{ }^{\circ} \mathrm{C}\right)
$$

where $\frac{\Delta f}{\Delta T}$ is the linear variation of frequency with the temperature. For the measured sample (a T-shaped with $350 \mu \mathrm{m}$ length and $50 \mu \mathrm{m}$ width), TCF is about $25 \mathrm{ppm} /{ }^{\circ} \mathrm{C}$ between $20^{\circ} \mathrm{C}$ and $100{ }^{\circ} \mathrm{C}$. We expect to improve this temperature dependency with $\mathrm{SiO}_{2}$ insulator layer under bottom electrode to compensate the temperature deviation.

\section{OSCILLATOR APPLICATION}

A first simple oscillator based on TFEAR resonator was designed and tested as illustrated on Figure 7: TFEAR based oscillator. Experimental values are: $A=3$ and $\mathrm{R}=680 \Omega$.

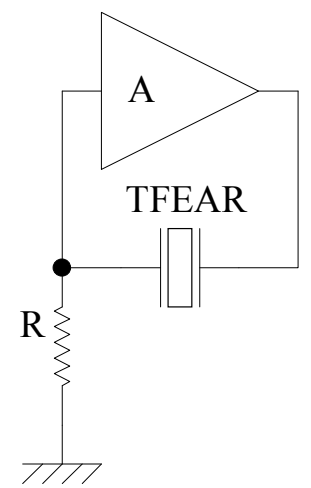

Figure 7: TFEAR based oscillator. Experimental values are: $A=3$ and $R=680 \Omega$.

The Barkhausen oscillation condition is:

$$
\underline{A} \underline{B}=1
$$

where $\underline{A}$ and $\underline{B}$ are gains of the amplifier and back loop respectively. $\underline{B}$ is given by:

$$
\underline{B}=\frac{R}{R+\underline{Z}_{\text {TFEAR }}}
$$

where $\underline{Z}_{T F E A R}$ is the impedance of the resonator and $R$ is the bridge resistance. The oscillation frequency is given by $\arg (\underline{A} \underline{B})=0$ and the gain is fixed by $|\underline{A} \underline{B}=1|$. Assuming $\frac{R_{m}}{R_{p}^{\prime}} \ll<1$ and $\frac{C_{m}}{C_{0}^{\prime}}<<1$, the solutions can be reduced to:

$$
\left\{\begin{array}{l}
\omega_{\text {osc }}=\frac{1}{2 \pi} \frac{1}{\sqrt{L_{m} C_{m}}}\left(1+\frac{C_{0}^{\prime} R_{m}^{2}}{2 L_{m}}\right) \\
A=1+\frac{R_{m}}{R}
\end{array}\right.
$$

Oscillator's amplifier is made using an AD8138 operational amplifier with an experimental gain of 3, and then $A B>1$ with all TFEAR tested. Used TFEAR resonator is a $X$-shaped $325 \mu \mathrm{m}$ length and $50 \mu \mathrm{m}$ width. We can notice frequency oscillation around $14.0540 \mathrm{MHz}$ closed to the expected performance $\left(\mathrm{f}_{\mathrm{osc}}=14.11 \mathrm{MHz}\right)$.

\section{CONCLUSION}

Thin film acoustic resonator operating on extensional mode in the range between $10 \mathrm{MHZ}$ to $50 \mathrm{MHz}$ has been fabricated and characterized. Performances of the TFEAR were improved with a $Q$ factor up to 2500 and a motional resistance lower than $400 \Omega$. The model, which takes into account electric substrate losses, enables to design a first oscillator. Oscillations were obtained, in the expected range, which demonstrates the working ability of these resonators. Study is in progress to confirm the potential of TFEAR to complete with quartz resonator for many applications requiring small size and CMOS compatible process.

\section{ACKNOWLEDGMENT}

The authors acknowledge J. Rouessard and A. Fougerat (NXP Semiconductors) for their support on characterization and ANSYS simulations, the clean room and characterization laboratory staff at NXP Semiconductors.

\section{REFERENCES}

[1] F. Verjus, L. Valbin, A. Fougerat, J. Rouessard, F. Le Cornec, S. Loiseau, "Piezoelectric Aluminium Nitride Resonator for reference Oscillator", in 2008 IEEE International Frequency Control Symposium Proceeding, Honolulu, May 18-21, 2008, pp. 233-236.

[2] C. T.-C. Nguyen, "MEMS technology for timing and frequency control", in IEEE Trans. On Ultrasonics, Ferroelectrics ans Frequency Control, vol. 54, pp. 251-270, Feb, 2007.

[3] K. Tsubouchi, K. Sugai, N. Mikoshiba, "AlN material constant evaluation and saw properties on $\mathrm{AlN} / \mathrm{AlO} /$ and AlN/Si, in IEEE Ultrasonics Symposium, pp. 375380, 1981.

[4] P. Muralt, J. Antifakos, M. Cantoni, R. Lanz, and F. Martin, "Is there a better material for thin film BAW applications than AlN?" in Proc. IEEE Ultrasonics Symp., Rotterdam, 2005, pp. 50-53.

[5] K. M. Lakin, "Equivalent Circuit Modeling of Stacked Crystal Filters", in 35th Annual Frequency Control Symposium, pp.257-262, 1981.

\section{CONTACT}

Laurie Valbin, tel: +33-145-926-647; 1.valbin@esiee.fr 